\title{
INVESTIGACIONES
}

\section{Análisis de las portadas de los libros de texto de Educación Física en Primaria}

\author{
Analysis of the covers of textbooks of Primary Physical Education
}

\author{
Irene Moya-Mata, ${ }^{a}$ Laura Ruiz Sanchís, ${ }^{b}$ Concepción Ros Ros $^{b c}$ \\ ${ }^{\mathrm{a}}$ Facultad de Magisterio, Universidad de Valencia \\ Telf.: (34) 6154755090. Correo electrónico: irene.moya@uv.es
}

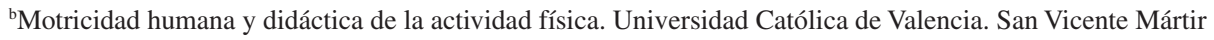
Telf.: (34) 655473776. Correo electrónico: laura.ruiz@ucv.es

'Telf.: (34) 630541431. Correo electrónico: concepción.ros@ucv.es

\section{RESUMEN}

Esta investigación analiza las imágenes del cuerpo humano y el tipo de actividad física que practica en las portadas de los libros de texto del área de Educación Física (EF) en Educación Primaria (EP), para determinar si reproducen y transmiten estereotipos en relación al sexo, raza, cuerpo, discapacidad y actividad física en función del currículum. La muestra universo consta de 30 portadas, publicadas bajo la Ley Orgánica de Educación (LOE). Los resultados muestran portadas preferentemente dibujadas y en color, los protagonistas de la actividad física son niños y niñas conjuntamente (agrupación mixta), pero a la vez permanecen estereotipos de raza (blanca) y somatotipo (ectomorfo) realizando actividad física deportiva, en ausencia de discapacidad. Se hace imprescindible una reflexión sobre los nuevos libros de texto de EF que se están implantando en nuestro sistema educativo, junto con el currículum oculto que subyace.

Palabras clave: libro de texto, imágenes, estereotipos, cuerpo, Educación Física.

\section{ABSTRACT}

This research analyzes the images of the human body and the type of physical activity practiced on the covers of textbooks in the area of Physical Education (PE) in Primary Education (EP) to determine if they reproduce and transmit stereotypes in relation to sex, race, body, disability and physical activity according to the curriculum. The sample universe consists of 30 covers, published under the Organic Law of Education (LOE). The results show covers preferably drawn and in color, the protagonists of physical activity are children, boys and girls (mixed group) jointly; there are yet some remaining stereotypes of race (white) and somatotype (ectomorph) when performing certain physical sports activity in absence of disability. It is essential to reflect on the new PE textbooks that are being implemented in our education system, along with the underlying hidden curriculum.

Key words: textbook, images, stereotypes, body, Physical Education. 


\section{INTRODUCCIÓN}

El libro de texto es una herramienta abierta y flexible que puede sugerir una forma de trabajo, de selección y organización del conocimiento, que ha ido afianzándose con el tiempo como elemento mediador en el diseño, desarrollo y evaluación del currículum escolar (Molina, Peiró \& Devís, 2004).

Frente a otros materiales didácticos, el libro de texto ofrece múltiples ventajas, según Vilcazán (2010): organiza mejor los contenidos y el trabajo al ofrecer una mayor cantidad de los mismos para su aprendizaje, es un buen documento de consulta, ofrece una visión más amplia del área al alumnado, generando conocimientos previos y dependiendo de su diseño es adaptable a la realidad, promoviendo la búsqueda de información.

A pesar de estas ventajas, en los libros de texto se recogen diferencias tanto en su texto escrito como en sus imágenes. Respecto a las imágenes publicadas en los libros de texto, Acaso y Nuere (2005) señalan que son un poderoso medio para la reproducción de estereotipos, ya que un elevado porcentaje de la información que llega a los jóvenes a través de las imágenes, se filtra en la conciencia colectiva sin reflexión previa.

Un estereotipo es una imagen, idea o modelo generalmente asociado a un grupo social, que es atribuido a sus conductas, cualidades y habilidades, así como a otras características que lo identifican y que, por lo general, son inmutables. Los estereotipos pueden ser positivos o negativos.

Las concepciones estereotipadas acerca del cuerpo (como construcción social), pueden transformarse en prejuicios (que son siempre de carácter negativo), que se manifiestan en etiquetas peyorativas o despectivas que causan un impacto negativo en los demás. Uno de los ámbitos donde se producen estos estereotipos es en la imagen fija del cuerpo, en las que no existe movimiento corporal (Correa, Guzmán \& Aguaded, 2000).

El ámbito de la actividad física y el deporte tampoco está exento de estereotipos. Estudios similares al nuestro los encontramos en el de Ramírez (2011), que analiza las portadas de videojuegos de género deportivo. Y más específicamente, el estudio de Herrador (2013) que analiza las portadas de diferentes libros de texto de EF en las etapas de educación secundaria obligatoria y bachillerato. Estas investigaciones concluyen que las imágenes fijas del cuerpo incluidas en estos soportes transmiten estereotipos y desigualdades de género, a pesar de la legislación vigente entre hombres y mujeres.

Concretamente, las ley de educación, LOE (2006), señala la inclusión educativa y la igualdad de derechos y oportunidades para superar cualquier tipo de discriminación, compensando las desigualdades sociales, culturales, personales y económicas que puedan darse, y resaltando las que puedan derivarse por cualquier tipo de discapacidad. La Ley Orgánica 1/2004, de 28 de diciembre, de Medidas de Protección Integral contra la Violencia de Género y la Ley Orgánica 3/2007, de 22 de marzo, para la igualdad efectiva de mujeres y hombres defienden que los materiales educativos deben favorecer la superación de todo tipo de estereotipos sexistas o discriminatorios, educando con total igualdad a hombres y mujeres e insistiendo en el respeto de todas las culturas.

Esto nos lleva a plantearnos la cuestión de si las imágenes presentes en las portadas de los libros de texto de EF en EP presentan estereotipos sexistas y discriminatorios relacionados con la actividad física, dificultando el logro de una sociedad igualitaria, dado que dentro de los procesos de interacción que se establecen se impulsa a las personas a adoptar roles específicos. 
Por todo ello, y con la finalidad de contribuir en esta línea de investigación, planteamos el siguiente objetivo de estudio: analizar las imágenes del cuerpo humano que aparecen en las portadas de los libros de texto de EF en la etapa de EP, valorando si transmiten o no estereotipos de género, raza, estructura corporal, discapacidad y actividad física presentes en la sociedad actual, bajo la ley educativa española LOE (2006).

\section{METODOLOGÍA}

\subsection{MUESTRA}

La muestra de esta investigación ha sido no probabilística, es decir, se han seleccionado los elementos de la muestra siguiendo unos criterios determinados, procurando que fuera lo más representativa posible.

Las unidades de muestreo han sido las imágenes aparecidas en las portadas de los libros de texto. Los criterios de selección de las portadas han sido los siguientes: portadas procedentes de los libros de texto de EF en EP, difundidos en lengua española, publicados en el sistema educativo español y editados desde el año 2007 hasta el 2013, bajo la ley educativa LOE. Se excluyeron las portadas de los libros de texto de EF en EP difundidos en otros idiomas, bajo otras leyes educativas, en las que no aparecía representada la figura humana o aparecía en otros materiales curriculares que no eran libros de texto. Por lo tanto, de 78 libros de texto encontrados, la muestra universo queda conformada por 30 portadas de libros de texto de EF en EP, perteneciente a cinco editoriales: Anaya, Bruño, Santillana, Serbal y Teide, tal y como se aprecia en la Figura 1:

Figura 1. Distribución de la muestra por editoriales



Fuente: elaboración propia. 


\subsection{DISEÑO}

El estudio realizado es de tipo descriptivo, empírico y no-experimental, al utilizar las portadas de los libros de texto como fuente documental y sin manipulación de variables (Sierra, 1993). Se utiliza el análisis de contenido como técnica central de la investigación, el cual permite la captación sistemática e interpretación del contenido de textos, fotos y películas (Heinemann, 2003).

\subsection{INSTRUMENTO}

Se elabora un sistema de categorías ad hoc para el análisis de las imágenes, a partir de un estudio anterior, en el que se analizan las imágenes de los libros de texto de EF del tercer ciclo de EP. Debido a que el objeto de estudio es más concreto, hemos reducido las dimensiones y sus respectivas categorías, validándose nuevamente.

El instrumento consta de las siguientes dimensiones y categorías: características técnicas de la imagen — tipología y color—, características del personaje — sexo, edad, raza, estructura corporal y discapacidad - y características de la actividad física — actividad realizada, bloque de contenido de EF, ámbito, espacio y nivel— (Tabla 1).

Tabla 1. Sistema de categorías para el análisis de las portadas de los libros de Educación Física

\begin{tabular}{|c|c|c|}
\hline DIMENSIÓN & CATEGORÍAS & INDICADORES \\
\hline \multirow{2}{*}{ Características técnicas de la imagen } & Tipología & $\begin{array}{l}\text { Dibujo } \\
\text { Fotografía }\end{array}$ \\
\hline & Color & $\begin{array}{l}\text { Color } \\
\text { Blanco y negro }\end{array}$ \\
\hline \multirow{5}{*}{ Características del personaje } & Sexo & $\begin{array}{l}\text { Masculino } \\
\text { Femenino } \\
\text { Mixto } \\
\text { No se distingue }\end{array}$ \\
\hline & Edad & $\begin{array}{l}\text { Niño } \\
\text { Joven } \\
\text { Adulto } \\
\text { Varios }\end{array}$ \\
\hline & Raza & $\begin{array}{l}\text { Blanca } \\
\text { Otras } \\
\text { Varias } \\
\text { No se distingue }\end{array}$ \\
\hline & Estructura corporal & $\begin{array}{l}\text { Endomorfo } \\
\text { Mesomorfo } \\
\text { Ectomorfo } \\
\text { Varias } \\
\text { No se distingue }\end{array}$ \\
\hline & Discapacidad & $\begin{array}{l}\text { Sí } \\
\text { No } \\
\text { No se distingue }\end{array}$ \\
\hline
\end{tabular}




\begin{tabular}{|c|c|c|}
\hline \multirow{5}{*}{ Características de la actividad física } & Actividad realizada & $\begin{array}{l}\text { Capacidades perceptivo- } \\
\text { motrices } \\
\text { Habilidades básicas } \\
\text { Condición Física } \\
\text { Expresivas } \\
\text { Actividad física saludable } \\
\text { Juegos } \\
\text { Deportes } \\
\text { Deportes adaptados } \\
\text { En la naturaleza } \\
\text { Complementarias } \\
\text { Varias } \\
\text { Otras } \\
\text { No se distingue }\end{array}$ \\
\hline & Bloque de contenido de EF & $\begin{array}{l}\text { Cuerpo: imagen y } \\
\text { percepción } \\
\text { Habilidades motrices } \\
\text { Expresión artística } \\
\text { Condición física y salud } \\
\text { Juegos y deportes } \\
\text { Varios } \\
\text { Otros }\end{array}$ \\
\hline & Ámbito & $\begin{array}{l}\text { Competitivo } \\
\text { Educativo } \\
\text { Recreativo } \\
\text { Utilitario } \\
\text { No se distingue }\end{array}$ \\
\hline & Espacio & $\begin{array}{l}\text { Deportivo } \\
\text { No deportivo } \\
\text { Medio Natural } \\
\text { No se distingue }\end{array}$ \\
\hline & Nivel & $\begin{array}{l}\text { Élite } \\
\text { No élite } \\
\text { No se distingue }\end{array}$ \\
\hline
\end{tabular}

\subsection{PROCEDIMIENTO}

El sistema de categorías se ha construido en cinco fases, siguiendo las indicaciones de Carretero-Dios y Pérez (2007):

- En la primera fase se realizó la prueba de pertinencia. A partir de un sistema de categorías anterior, lo adaptamos para analizar las imágenes de los libros de EF en Primaria. Una vez adaptado el instrumento, se aplica sobre 10 portadas de libros de texto de EF en Primaria seleccionadas de diferentes editoriales, mediante un muestreo casual. La finalidad de esta fase fue comprobar la adecuación de 
esta herramienta al objeto de estudio, reelaborando el sistema de categorías a las imágenes de las portadas analizadas.

- $\quad$ En la segunda fase se realizó el panel compuesto por 10 jueces expertos, con la finalidad de validar la metodología propuesta, así como el instrumento elaborado para dicho fin.

- En la tercera fase se reelaboró el instrumento a partir de las respuestas de cada uno de los jueces expertos, tras las cuales se modificaron algunas categorías e indicadores de dicho instrumento y se volvió a enviar a los jueces expertos.

- En la cuarta fase se llevó a cabo la triangulación de tres observadores, uno de ellos fue la propia investigadora. Se efectuó un proceso previo de entrenamiento de los observadores, para familiarizarlos con las imágenes objeto de análisis y el instrumento de recogida de la información.

- En la quinta y última fase se aplicó la metodología de investigación definida en las fases anteriores, correspondiente con el análisis de la muestra.

\subsection{ANÁLISIS ESTADÍSTICO DE LOS DATOS}

Se realizó un análisis descriptivo del cual se extrajo el porcentaje de frecuencia de la clasificación de las portadas de los libros de EF en la LOE y en castellano $(n=30)$, mediante el paquete estadístico SPSS 19.0. Se obtuvo el número de portadas que tanto en valores absolutos como en valores porcentuales ha mencionado cada uno de los códigos posibles de la clasificación que puede tomar la variable editorial.

Posteriormente se realizaron tablas de contingencia que analizan la distribución de frecuencia conjunta de dos variables de tipo cualitativo, las medidas de asociación entre las diferentes variables son sexo, actividad física y ciclos. Para conocer si la correlación entre dos variables es significativa, se demanda también el estadístico de contraste Ji-Cuadrado de Pearson $(\chi 2)$, fijando el nivel de significación en el 5\% $(\alpha=.05)$.

\section{RESULTADOS}

En cuanto a las características técnicas de la imagen, observamos que el 100\% de las portadas analizadas aparecen en color y que la "tipología de la imagen" en la portada presenta diferencias, el formato más elegido es el "dibujo" en un 66\%. Esta frecuencia se invierte en Serbal, cuyo 100\% es "fotografía" y en Anaya donde encontramos un 50\% para cada tipología de imagen. En la Figura 2 se observan las diferencias en porcentajes: 
Figura 2. Tipología de la imagen en las portadas de las editoriales de EF en Primaria

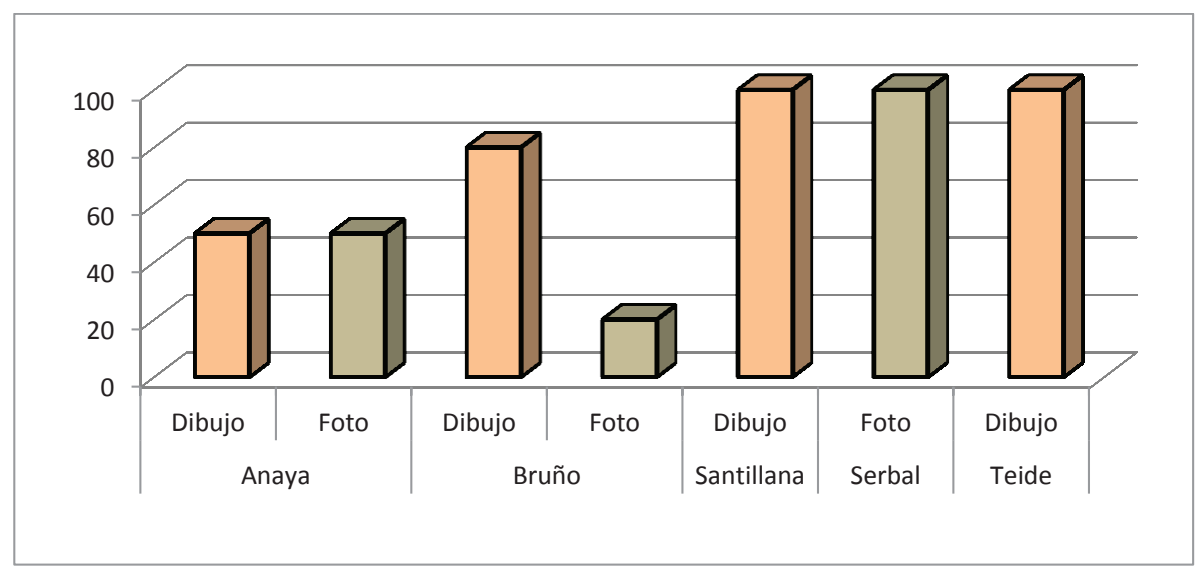

Fuente: elaboración propia.

Con respecto a la distribución del "sexo" en la imagen de las portadas, la representación más frecuente es la "mixta" (hombre-mujer) con un 56\%, seguida de la "masculina" 22\% y la "femenina" $12 \%$. Respecto a las editoriales, se observan diferencias: Anaya es la editorial que presenta un 50\% para la "masculina" y un 50\% para la "femenina". En la editorial Serbal se aprecian diferencias: la imagen "masculina" se presenta en un $75 \%$ y la femenina en un $25 \%$. Santillana y Teide evidencian un $100 \%$ de representación "mixta" y, finalmente, Bruño muestra un $10 \%$ para la representación "masculina" y "femenina", mientras el 80\% es representación "mixta", como se detalla en la Figura 3.

Figura 3. Distribución de los sexos en la imagen las portadas de las editoriales de Primaria

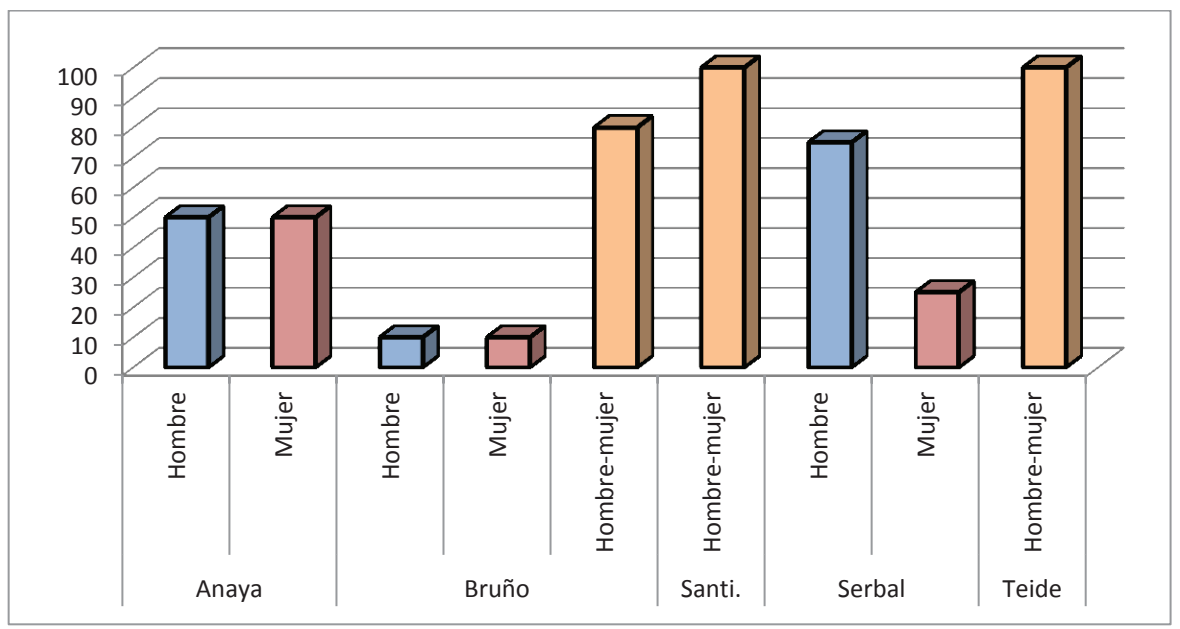

Fuente: elaboración propia. 
Sobre los datos relativos a la distribución de edades en las imágenes, es la imagen del "niño", con un $88 \%$, la más representada. Anaya es la editorial que presenta dos tipologías: el $75 \%$ niño y el $25 \%$ joven.

La distribución según "raza" muestra que el mayor porcentaje es el de la raza "blanca" con un 62\%, frente a "varias" con un 38\%. Como se observa en la Figura 4, las editoriales presentan diferencias. Anaya con un $100 \%$ de portadas con representación de raza "blanca", Serbal un 50\% para raza "blanca" y un 50\% para "varias" razas y Teide con un $33 \%$ de raza "blanca" frente a un $67 \%$ de "varias".

Figura 4. Distribución por razas en las portadas de las editoriales de Primaria

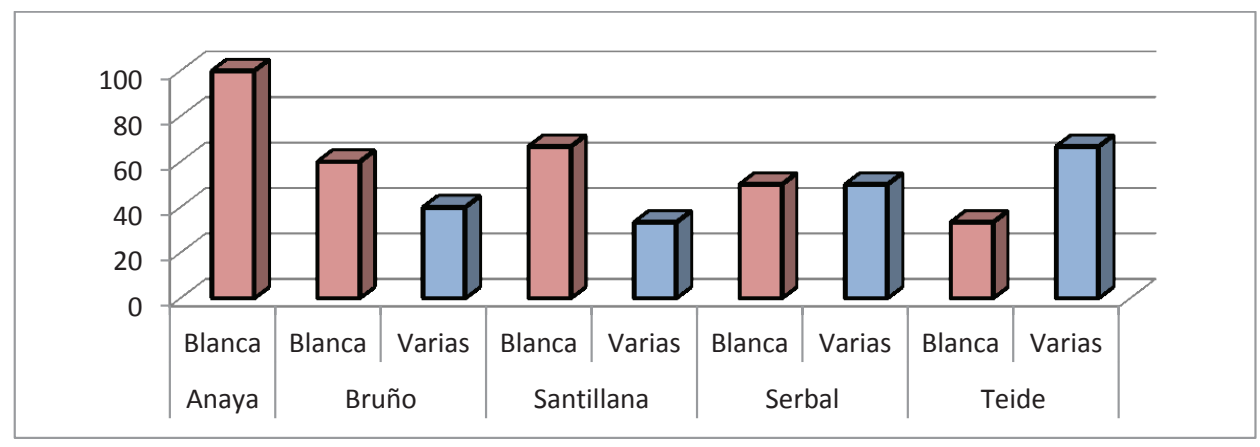

Fuente: elaboración propia.

Sobre los datos de la "actividad realizada", los "deportes" son los más representados, con un $48 \%$, seguido de los "juegos" con $22 \%$. Ambos se unen en el bloque de "Juegos y deportes" que representa el $70 \%$ de las portadas. Las "capacidades perceptivo-motrices" se representan con un 20\% dentro del bloque "El cuerpo: imagen y percepción" con un 20\%, un 5\% para las "capacidades físicas" representadas en el bloque "Habilidades y destrezas" y un 5\% para "otras" actividades físicas. Se observan diferencias entre las editoriales, Anaya es la editorial que presenta un $75 \%$ de "deportes" y un $25 \%$ de "capacidades perceptivomotrices", con una distribución parecida a la de Santillana con un 66,7\% "deportes" y un 33,3\% para "capacidades perceptivo-motrices". Es llamativa la distribución de Bruño con un $70 \%$ de "juegos" y un 30\% "deportes". En la Figura 5 se observan los porcentajes. 
Figura 5. Tipo de actividad física en las portadas de las editoriales de Primaria

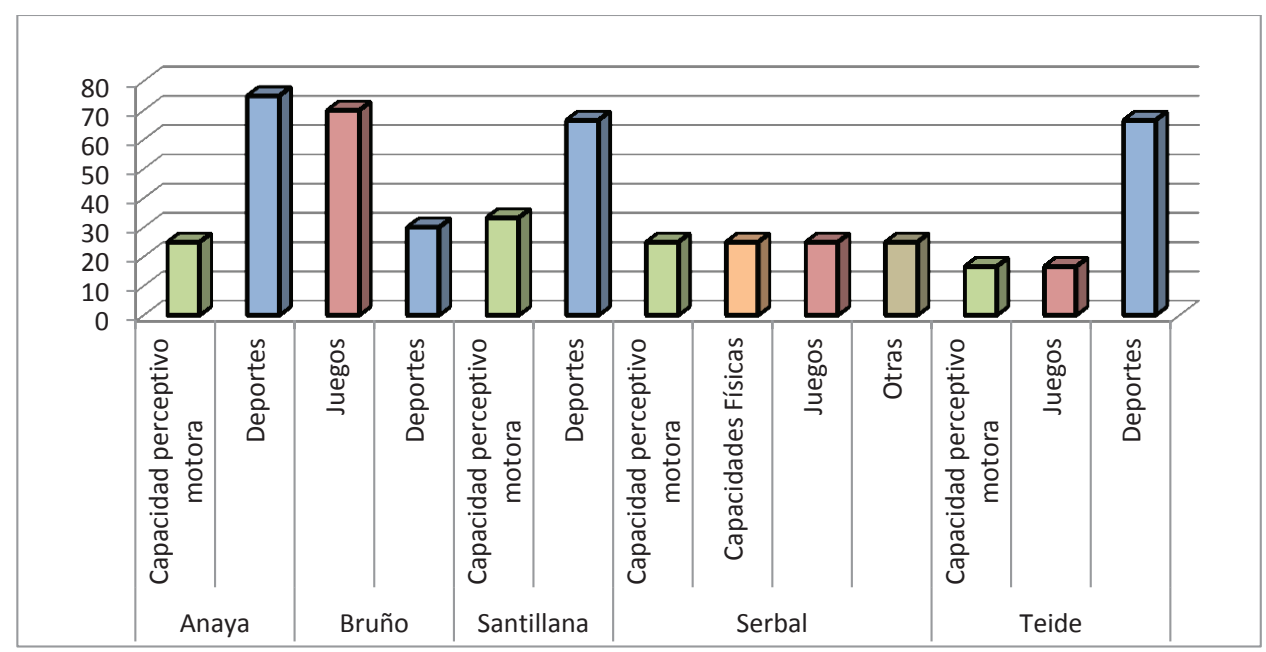

Fuente: elaboración propia.

Con respecto al "ámbito" de práctica realizada, el más representado es el "recreacional" con un $46 \%$, que podemos relacionar con el "espacio" de práctica "no se distingue" en un $84 \%$, frente al ámbito "competitivo" con un $10 \%$ y un "espacio" de práctica de un $3 \%$, el $44 \%$ es de imágenes de un ámbito no reconocible. Nuevamente se observan diferencias entre editoriales: Anaya presenta el 100\% de las imágenes en el ámbito "recreacional", Bruño el $90 \%$ y Santillana un 33\% y Serbal un 16,7 \% de "competitivo". Lo anterior se aprecia en la Figura 6, a continuación.

Figura 6. Ámbito de práctica de actividad física en las portadas de las editoriales de Primaria

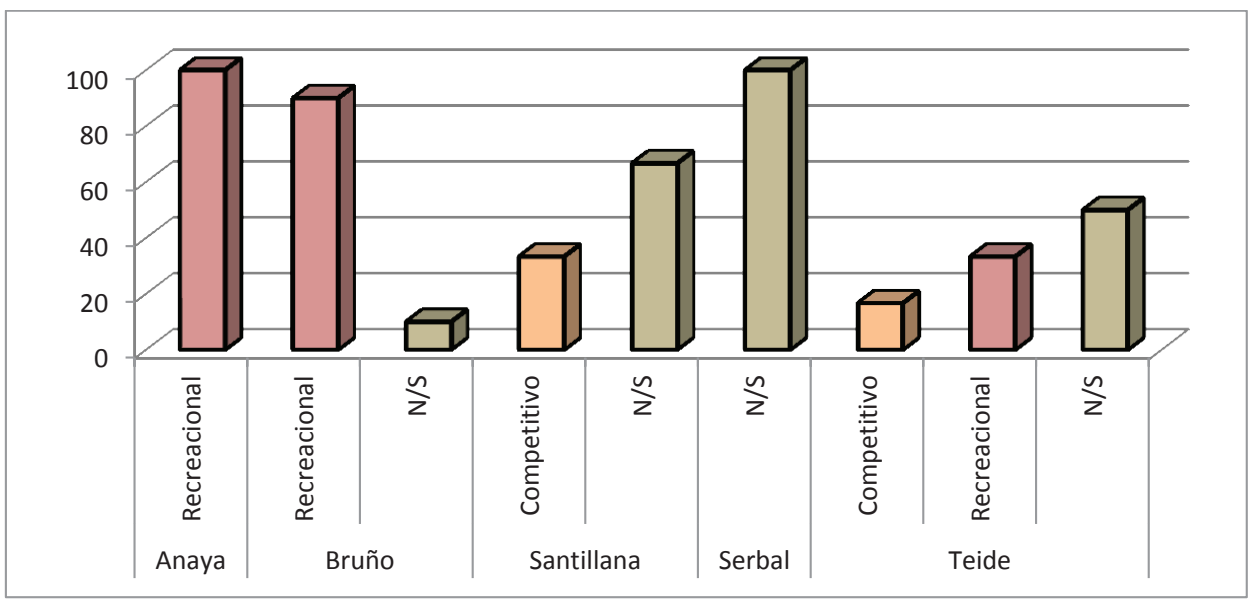

Fuente: elaboración propia. 
Finalmente, destacamos el "nivel" de práctica de actividad física. En dicho ámbito el $73 \%$ representa "no élite" y el $27 \%$ "no se distingue". Entre editoriales no existen grandes diferencias respecto a esta variable.

Cuando hablamos de los ciclos que forman parte de la Educación Primaria se observan diferencias en algunas categorías. Respecto a la distribución de sexos en las imágenes se observa que el sexo "masculino" solo lo encontramos en primer ciclo en un $20 \%$ y el $80 \%$ restante para el grupo "mixto". En el segundo ciclo, el 18,5\% es para el sexo "masculino", el 9,1\% para el sexo "femenino" y el 72,7\% para el grupo "mixto". En el tercer ciclo se invierte la tendencia, el sexo "femenino" es la imagen que aparece en un 33,3\%, el "masculino" en un 22,2\% y el "mixto" en un 44,4\%. Se aprecia la siguiente disposición en la Figura 7:

Figura 7. Distribución de sexo en las imágenes por ciclos de Primaria

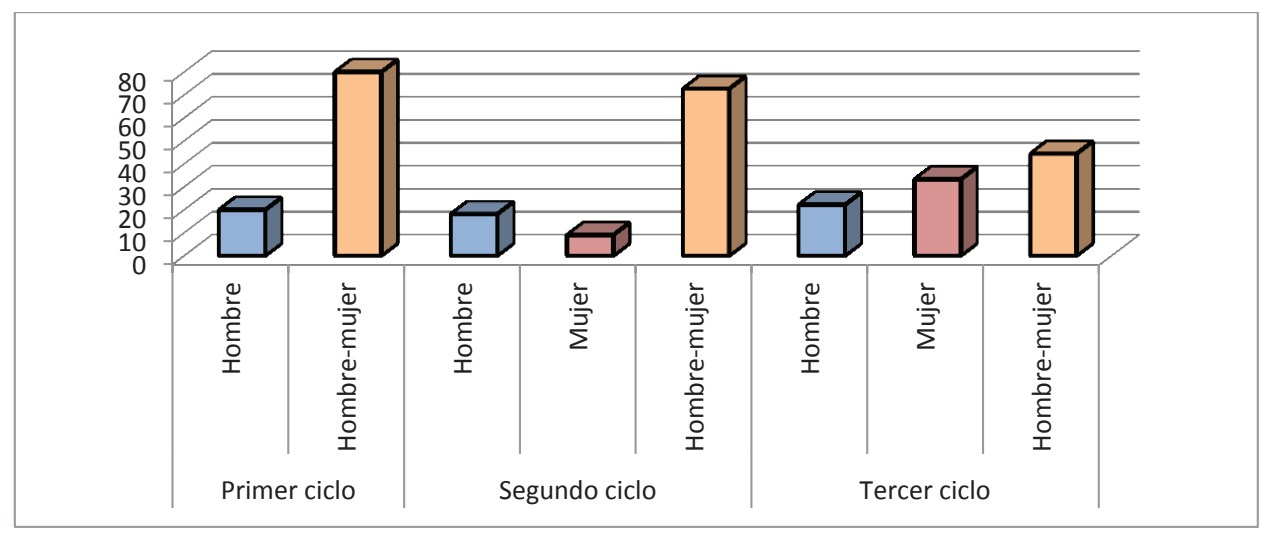

Fuente: elaboración propia.

Las variables de la distribución de la edad de las imágenes en las portadas, así como la distribución en razas es equivalente en todos los ciclos.

En el caso de la "estructura corporal" en la imagen, podemos destacar que en el primer ciclo el 100\% es "ectomorfo"; en el segundo ciclo encontramos un 81,8\% de "ectomorfo", un $9,1 \%$ "mesomorfo" y un $9,1 \%$ de "varias" estructuras corporales; en el tercer ciclo vuelve a ser $100 \%$ "ectomorfo", como podemos observar en la Figura 8. 
Figura 8. Somatotipo en las imágenes por ciclos de Primaria

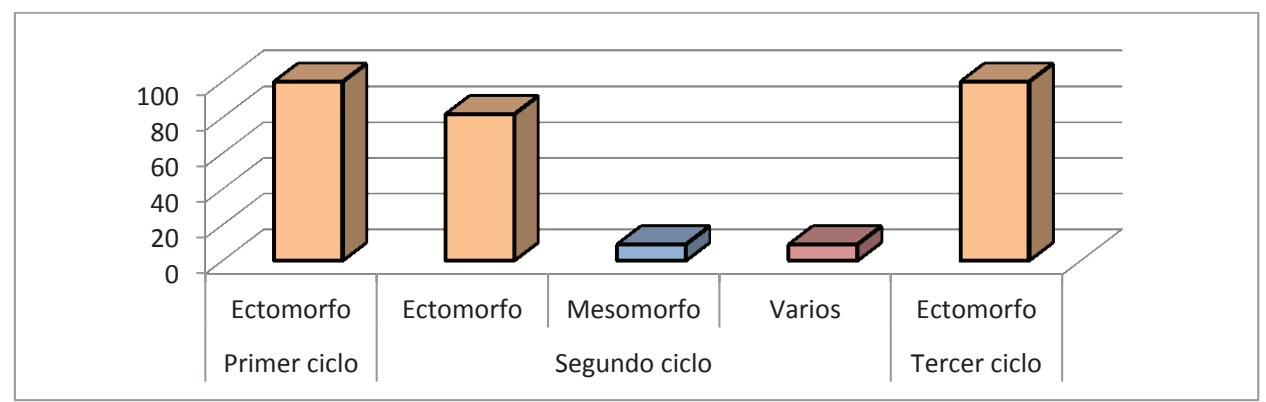

Fuente: elaboración propia.

En la variable "discapacidad", solo encontramos una imagen perteneciente a $6^{\circ}$ de Primaria, por lo tanto, en el tercer ciclo, con un $3 \%$ de representatividad.

En relación a la "actividad realizada", los descriptivos nos muestran diferencias en las frecuencias. La "actividad realizada" en el primer ciclo corresponde a $40 \%$ de "juegos", un $30 \%$ de "capacidad perceptivo motora", un $20 \%$ de "deportes" y un $10 \%$ de "otras". Para el segundo ciclo el 45,5\% es para "juegos" y el otro 45,5\% para "deportes", mientras que el $9 \%$ es para "capacidad perceptivo motora". Finalmente, en el tercer ciclo el $78 \%$ son representaciones de "deportes" y el $11 \%$ se relaciona tanto con "capacidades físicas" como con "capacidad perceptivo motora". Ello se aprecia en la Figura 9.

Figura 9. Tipo de actividad física en las imágenes por ciclos de Primaria

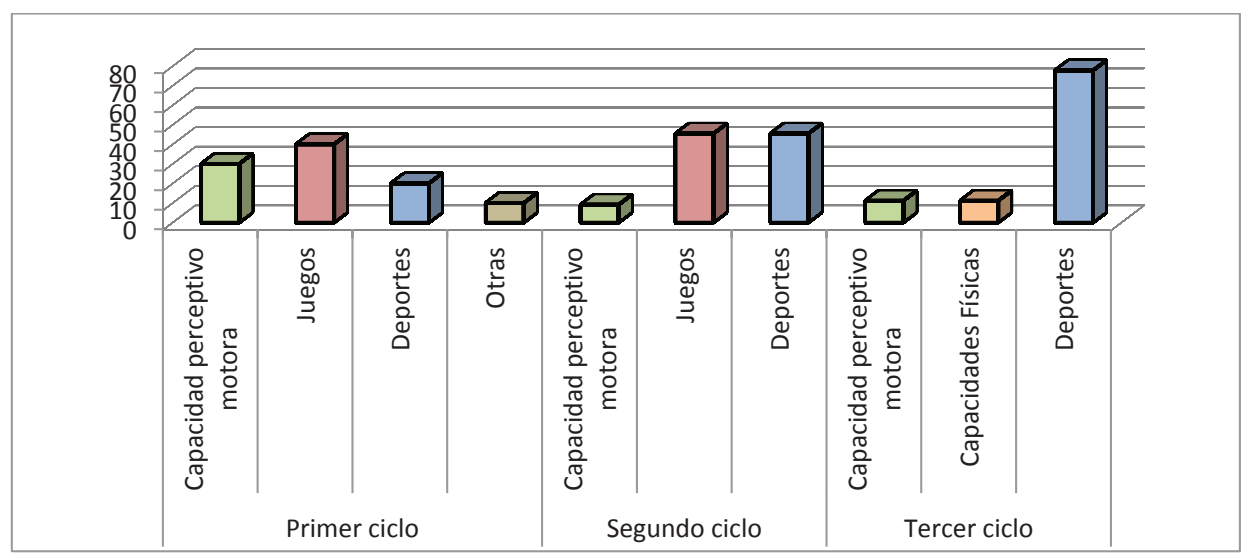

Fuente: elaboración propia.

Dentro de la selección de los bloques de contenido de EF por ciclos podemos observar que el bloque más seleccionado para representar las portadas es el de "juegos y deportes" 
en un $75,6 \%$ de las imágenes, distribuido de la siguiente manera: para el primer ciclo un $60 \%$ de "juegos y deportes", un 30\% para "el cuerpo: imagen y percepción" y un 10\% de "otros". En el segundo ciclo, el 90,9\% es para "juegos y deportes" y el 9,1\% para "el cuerpo: imagen y percepción". Finalmente, en el tercer ciclo un 77,8\% es para los "juegos y deportes", un 11,1\% para "habilidades y destrezas" y el otro 11,1\% para "el cuerpo: imagen y percepción". Como se aprecia en la Figura 10.

Figura 10. Bloques de contenido de Educación Física por ciclos en Primaria

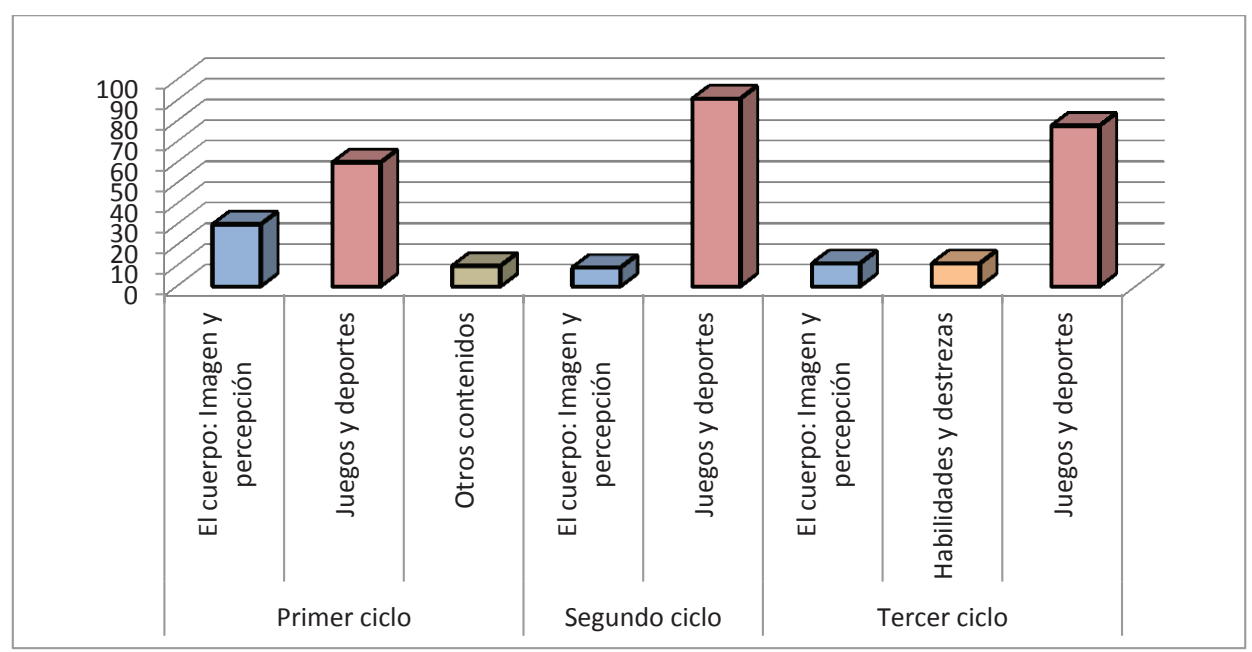

Fuente: elaboración propia.

El "espacio" deportivo que predomina en los tres ciclos corresponde a "no se distingue" o "no deportivo"; es el último ciclo el único con un $20 \%$ en "medio natural" y $20 \%$ en espacio "deportivo".

Finalmente, en todos los ciclos el nivel de actividad de práctica es de no élite (100\%).

Las tablas de contingencia y los resultados de la prueba Ji-Cuadrado muestran dependencia entre la distribución del "sexo" en relación a las "editoriales" $(p=.02)$, la "actividad realizada" y la "editorial" $(p=.02)$. Para los ciclos únicamente encontramos relación en la variable "actividad realizada" $(p=0.4)$.

Los resultados de la prueba Ji-Cuadrado muestran dependencia entre la distribución de "sexo" y "editoriales"; en el caso de los "hombres" se puede afirmar que se vinculan mayoritariamente a la editorial Serbal $(t=2.34 ; p=.01)$, mientras que las "mujeres" lo hacen a la editorial Anaya $(t=4.04 ; p=.01)$. Para la "actividad realizada", es Bruño la editorial con más "juegos" ( $t=1.22 ; p=.00)$ y Santillana con más "habilidades perceptivo motoras" ( $t=3.12 ; p=.01)$. Para la relación "ciclo" y "actividad realizada" es en el tercer ciclo, los "deportes" $(t=4.17 ; p=.01)$ y la "capacidad perceptivo motora" en el primer ciclo $(t=4.17 ; p=.00)$. 


\section{DISCUSIÓN}

Las características técnicas de las imágenes contenidas en las portadas analizadas son exclusivamente en color, al igual que las portadas de videojuegos (Ramírez, 2011), pero predomina la viñeta dibujada frente a la fotografía.

Una de las categorías de análisis más relevantes es el "sexo" de los personajes: es el "grupo mixto" la categoría más representada en las portadas de los libros de texto, seguido de la categoría "masculina" y "femenina", respectivamente. Estos resultados difieren de los estudios de Ramírez (2011) y Herrador (2013) en donde predomina el sexo masculino en las portadas, tanto de videojuegos como de libros de texto.

Referente a la edad de los protagonistas, destacan los "niños" como el rango más común, frente a los "jóvenes" en las portadas de los videojuegos (Ramírez, 2011). Ello puede deberse al destinatario del material.

En cuanto a la "raza" de los personajes, independientemente de la editorial analizada, el indicador con mayor presencia es la representación de la raza "blanca"; es llamativo el $100 \%$ en la editorial Anaya. Este resultado también coincide con Ramírez (2011), demostrando que no hay diversidad en las imágenes representadas, aun habiendo un $36 \%$ de alumnado extranjero en la etapa de Primaria en España según el Libro Verde de Inmigración y Movilidad (Comisión Europea, 2008). En dos estudios similares, tanto González, Táboas y Rey (2010), que analizaron los libros de texto de EF en Secundaria durante la vigencia de las leyes orgánicas de educación LOGSE y LOE (1990-2006), como en un estudio anterior en el que analizamos los libros de texto de EF del tercer ciclo de Primaria, se comprobó que la representación racial "blanca" fue mayor, comparada con otras representaciones raciales, incluso en ambos periodos legislativos. Estos resultados contrastan con lo establecido en la LOE (2006), que pretende garantizar la igualdad de oportunidades, independientemente de las características personales, culturales, económicas o sociales.

Otro aspecto relevante es la estructura corporal que aparece en las portadas. Los resultados de esta categoría destacan el predominio del somatotipo "ectomorfo" o delgado, muy por encima del "mesomorfo" o del "endomorfo", independientemente de la editorial analizada. Estos datos difieren del estudio de Ramírez (2011) en donde predomina la estructura corporal mesomorfa, entre otros factores que explican este resultado puede mencionarse la imagen fotográfica de las portadas de los videojuegos, frente a la viñeta dibujada que prevalece en las portadas de los libros de texto de EF en Primaria.

Con respecto a la categoría "discapacidad", se puede decir que es invisible, ya que solo se representa en una portada de las 30 analizadas; es decir, representa el 3\% de las imágenes. Esta escasa presencia se confirma en investigaciones anteriores relacionadas con los libros de texto en Primaria (Martínez-Bello, 2014) y en el área de EF en la etapa de Secundaria (González \& Rey, 2013; Táboas \& Rey, 2012b); ya que en los estudios referentes a las portadas no se contempla esta categoría. En la misma línea, pero en los Estados Unidos, Hardin y Hardin (2004) mostraron que las personas con algún tipo de discapacidad no se representan lo suficiente y tienen baja vinculación con las actividades físicas. En relación a las editoriales se puede afirmar que Santillana es la única editorial que representa la diversidad en sus portadas, aunque el porcentaje sea mínimo frente al resto de editoriales. Promulgándose bajo la LOE (2006) principios de atención a la diversidad y de escuela inclusiva, con especial atención a las derivadas de cualquier tipo de discapacidad, se puede sostener que este objetivo no podrá alcanzarse hasta que las personas con algún 
tipo de discapacidad se visibilicen y sean representadas, por ejemplo, en las imágenes de los libros de texto (Figura 11).

Figura 11. Presencia de la discapacidad en la portada del libro de texto.

Educación Física. 6 Primaria. Santillana (2013)

\section{Educación física 6 PRIMARIA}

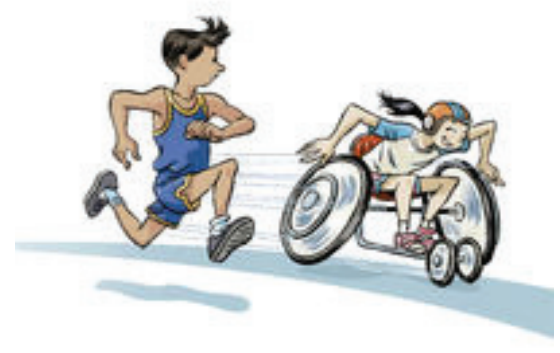

En relación con la actividad física realizada, los "deportes" son los que destacan, muy por encima del resto de actividades físicas; por lo que se puede afirmar que las portadas transmiten una deportivización del currículum de EF. Este resultado no solo coincide con Ramírez (2011) en el tipo de actividad física realizada, sino en el tipo de deporte reproducido (baloncesto), muy por encima del deporte rey (fútbol).

Este resultado se relaciona directamente con los "bloques de contenido" del currículum de EF en EP, del Real Decreto 1513/2006, en el que predomina el bloque de "Juegos y deportes" frente al resto de contenidos del currículum de EF. Esta clara desproporción en la que prevalecen las actividades deportivas frente al resto de posibilidades de práctica motriz lo confirman diferentes estudios en los libros de texto de EF en Secundaria y Bachillerato (Díaz, 2003; González, 2005; Parra, 2001; Táboas \& Rey, 2012a). Todos los estudios coinciden en la escasa representación del resto de bloques de contenidos en las imágenes, siendo omitidos los bloques relacionados con la expresión corporal y las actividades en el medio natural. Esta descompensación de las actividades físicas contradice el Real Decreto 1513/2006, que señala que "a lo largo de la etapa se debe promover y facilitar que el alumno domine un número variado de actividades corporales y deportivas".

Por último, se debe destacar el alto porcentaje de portadas en las que tanto el "ámbito" como el "espacio de práctica" no se distinguen, y que pensamos puede deberse al predominio de la viñeta dibujada, ya que esta no es tan detallada en cuanto a elementos en la imagen, y por lo tanto no se obtiene información suficiente para poder realizar la clasificación correspondiente. Aunque diferimos del estudio de Ramírez (2011) con respecto al "nivel" 
de práctica, pues en nuestro caso es de "no élite", frente a la "élite" de las portadas de los videojuegos deportivos.

\section{CONCLUSIONES}

Las portadas de los libros de texto de EF en EP editadas bajo la LOE (2006) representan una agrupación mixta, de raza blanca, con un somatotipo delgado tanto en hombres como en mujeres; ambos practican actividad física asociada al bloque de contenido "Juego y deporte" y sin discapacidad.

De estas conclusiones se deduce que las portadas de los libros de texto de EF en la EP, editados en el periodo de la LOE (2006), mantienen estereotipos de raza, cuerpo y actividad física; independientemente que se promulguen artículos y leyes destinadas a la igualdad de género. Asimismo, la invisibilidad de la discapacidad sigue siendo una constante en las imágenes relacionadas con la actividad física y el deporte. Por ello consideramos primordial que las editoriales y administraciones educativas vayan en la misma dirección para mejorar estos materiales curriculares, erradicando estereotipos tan consolidados y arraigados en nuestro sistema educativo. Aunque cabe destacar un cambio positivo en algunas editoriales, al publicar imágenes más coeducativas en sus portadas.

Como propuesta para futuras investigaciones sería interesante ampliar la muestra a las etapas educativas de Secundaria y Bachillerato, así como analizar las imágenes que aparecen en su interior.

\section{REFERENCIAS BIBLIOGRÁFICAS}

Acaso, M., \& Nuere, S. (2005). El currículum oculto visual: aprender a obedecer a través de la imagen. Arte, Individuo y Sociedad, 17, 205-218.

Carretero-Dios, H., \& Pérez, C. (2007). Normas para el desarrollo y revisión de estudios instrumentales: consideraciones sobre la selección de test en la investigación psicológica. International Journal of Clinical and Health Psychology, 7(3), 863-882.

Comisión Europea. (2008). Libro verde, inmigración y movilidad: Retos y oportunidades de los sistemas educativos de la UE. Documentos COM, 423, 1-17.

Correa, R., Guzmán, M., \& Aguaded, J. (2000). La mujer invisible. Una lectura disidente de los mensajes publicitarios. Huelva: Grupo Comunicar.

Díaz, B. (2003). Los libros de texto como instrumentos de deportivización del currículo real de la Educación Física. Revista Digital Lecturas: Educación Física y Deportes, 56. Recuperado de http://www.efdeportes.com/efd56/texto.htm

González, A., Táboas, M. I., \& Rey, A. (2010). Los libros de texto como herramientas para la promoción de una práctica físico deportiva en igualdad: análisis comparativo de la representación racial entre los libros publicados durante la vigencia de la LOGSE y la LOE. Cuadernos de psicología del deporte, 10(3), 31-36.

González, A., \& Rey, A. (2013). Cultura corporal y estereotipos en las imágenes de libros de texto de educación física publicados bajo el periodo de la Ley Orgánica de Educación (LOE). Ágora para la Educación Física y el Deporte, 15(1), 1-19.

González, M. (2005). ¿Tienen sexo los contenidos de Educación Física Escolar? Transmisión de estereotipos de sexo a través de los libros de texto en la etapa de Secundaria. Revista Internacional de Medicina y Ciencias de la Actividad Física y el Deporte, 5(18), 77-88. Recuperado de http:// 
cdeporte.rediris.es/revista/revista18/artsexismo8.htm

Hardin, B., \& Hardin, M. (2004). Distorted pictures: images of disability in physical education textbooks. Adapted Physical Activity Quarterly, 21, 399-413.

Heinemann, K. (2003). Introducción a la metodología de la investigación empírica. Barcelona: Paidotribo.

Herrador, J. (2013). Estereotipos sexistas en el ámbito educativo: Análisis de los libros de educación física. Tándem: Didáctica de la educación física, 41, 22-29.

Ley Orgánica 1/2004, de 28 de diciembre, de Medidas de Protección Integral contra la Violencia de Género. Madrid: MEC.

Ley Orgánica 3/2006, de 3 de mayo, de Educación (LOE). Madrid: MEC.

Martínez-Bello, V. (2014). Cuerpos silenciados y educación inclusiva: análisis de las imágenes de libros de texto españoles de educación primaria. Revista Latinoamericana de Educación Inclusiva, 7(2), 213, 229.

Molina, J. P., Peiró, C., \& Devís, J. (2004). Un estudio sobre los materiales curriculares impresos en Educación Física: implicaciones para la formación del profesorado. Movimiento. Revista da Escola de Educação Física, 10(1), 41-70.

Parra, J. (2001). Análisis del sexismo en los libros de texto de Educación Física: $2^{o}$ ciclo de ESO y Bachillerato (Tesis doctoral inédita). Universidad Nacional de Educación a Distancia, Castilla La Mancha.

Ramírez, G. (2011). Estereotipos corporales en las portadas de los videojuegos de género deportivo. Revista Internacional de Medicina y Ciencias de la Actividad Física y el Deporte, 11(42), 407420.

Real Decreto 1513/2006, de 7 de diciembre, por el que se establecen las enseñanzas mínimas de la educación primaria. Madrid: MEC.

Sierra, R. (1993). Tesis doctorales y trabajos de investigación científica. Madrid: Paraninfo.

Táboas, M. I., \& Rey, A. (2012a). Los contenidos de la Educación Física en Secundaria: un análisis de las actividades físicas que se enseñan en las imágenes de los libros de texto. Apunts. Educación Física y Deportes, 107, 45-53. doi:10.5672/Apunts.2014-0983.es.(2012/1).107.04

Táboas, M. I., \& Rey, A. (2012b). Disability in Physical Education Textbooks: An Analysis of Image Content. Adapted Physical Activity Quarterly, 29(4), 310-328.

Vilcazán, E. (2010). Uso del libro en el área de Educación Física en Primaria. Una propuesta teórico-práctica. Revista digital: Educación Física y Deportes, 143. Recuperado de http://www. efdeportes.com/efd143/uso-del-libro-en-el-area-de-educacion-fisica.htm 